\title{
Sistema de controle e automação para irrigação
}

\author{
Luana Helena Oliveira Monteiro ${ }^{1}$, Gissandro May Dantas Gama ${ }^{1}$, Frank do \\ Nascimento Ferreira $^{1}$, Alexandre Silva de Sousa Junior ${ }^{1}$, Fabrício Sousa da \\ Conceição ${ }^{1}$, José Felipe Souza de Almeida ${ }^{1}$
}

${ }^{1}$ Universidade Federal Rural da Amazônia -UFRA

Belém - PA - Brasil

eng.luanamonteiro@gmail.com, gissandrogama@gmail.com,

frankdonascimentojr@gmail.com, alexandresilva933@gmail.com,

fabricio.sousweb@gmail.com, wirelinux@gmail.com

\begin{abstract}
The study presents the importance of the information system to manage irrigation in plantations through an application and aims to automate and control the agricultural production process, minimizing waste of water. The system will be managed via web and mobile interface, through an application called Irrisusten. The physical part will consist of Arduino Uno components, ground sensor module, $5 v$ relay module, $12 v$ battery, led, resistors, solenoid valve, bluetooth HC-05 or HC-06 module, protoboard, jumps and USB cable.
\end{abstract}

Resumo. O estudo apresenta a importância do sistema de informação para gerenciar a irrigação em plantações através de uma aplicação e tem como objetivo automatizar e controlar o processo de produção agrícola, minimizando o desperdício de água. O sistema será gerenciado via interface web e mobile, através de aplicativo denominado Irrisusten. A parte física será composta por componentes Arduino Uno, módulo sensor de solo, módulo relé de $5 v$, bateria de $12 v$, led, resistores, válvula solenoide, módulo bluetooth $\mathrm{HC}$ 05 ou HC-06, protoboard, jumps e cabo USB.

\section{Introdução}

Hoje no Brasil existem diversas tecnologias disponíveis voltadas para o meio agrícola, porém são tecnologias caras que necessitam de grande investimento, fazendo com que agricultores de pequeno e médio porte não tenham total acesso a essas novas maneiras de trabalho (BARBOSA, 2013). A agricultura é essencial para o ser humano, mas é também um dos setores que mais consome água no Brasil e em todo o mundo. Recentemente a irrigação vem sendo uma das tecnologias mais utilizadas por agricultores, pois independentemente da ocorrência de chuvas ou não, garante aos produtores uma safra uniforme e minimiza os riscos de perdas por falta de água e otimiza o consumo, além de requerer um sistema de irrigação vantajoso que evite desperdício e distribuição do recurso natural de maneira inteligente ao longo do cultivo.

A facilidade de modificar equipamentos e de criar programas levou ao crescimento de soluções de software e hardware e foi decisivo para a construção do conhecimento e avanço tecnológico, e que fornecem componentes economicamente viáveis para a Internet das Coisas (IoT) (SABTAELLA et al., 2013). A IoT integra qualquer dispositivo por intermédio de redes computacionais, interligando $\mathrm{e}$ 
mecanizando diversas tarefas cotidianas gerando dados informacionais, considerado por Lucas, Ballay e McManus (2012) como o futuro da Era da Informação.

O presente trabalho apresenta como objetivo o desenvolvimento de um sistema de irrigação tendo por base a plataforma Arduino e demais componentes eletrônicos para controle automático de válvulas solenoides, que a partir dos dados de leitura do solo realizada por sensores, controlam a irrigação do cultivo, já que a umidade e resistência elétrica do solo são propriedades relacionadas.

\section{Material e Métodos}

O sistema será gerenciado via interface web e mobile, através de aplicativo dedicado (Figura 1), com os menus: Agenda, Histórico e Configurações, permitindo configurar e criar regras de irrigação com base em dias ou horários e dados do sensor de umidade de solo. As regras de irrigação serão executadas de uma unidade controladora de acordo com a programação do usuário, levando em consideração as informações obtidas pelos sensores de umidade. A primeira versão do IrriSusten será para o sistema Android, e terá como base o seu desenvolvimento a linguagem de programação Java.

Figura 1 - Layout do aplicativo IrriSusten
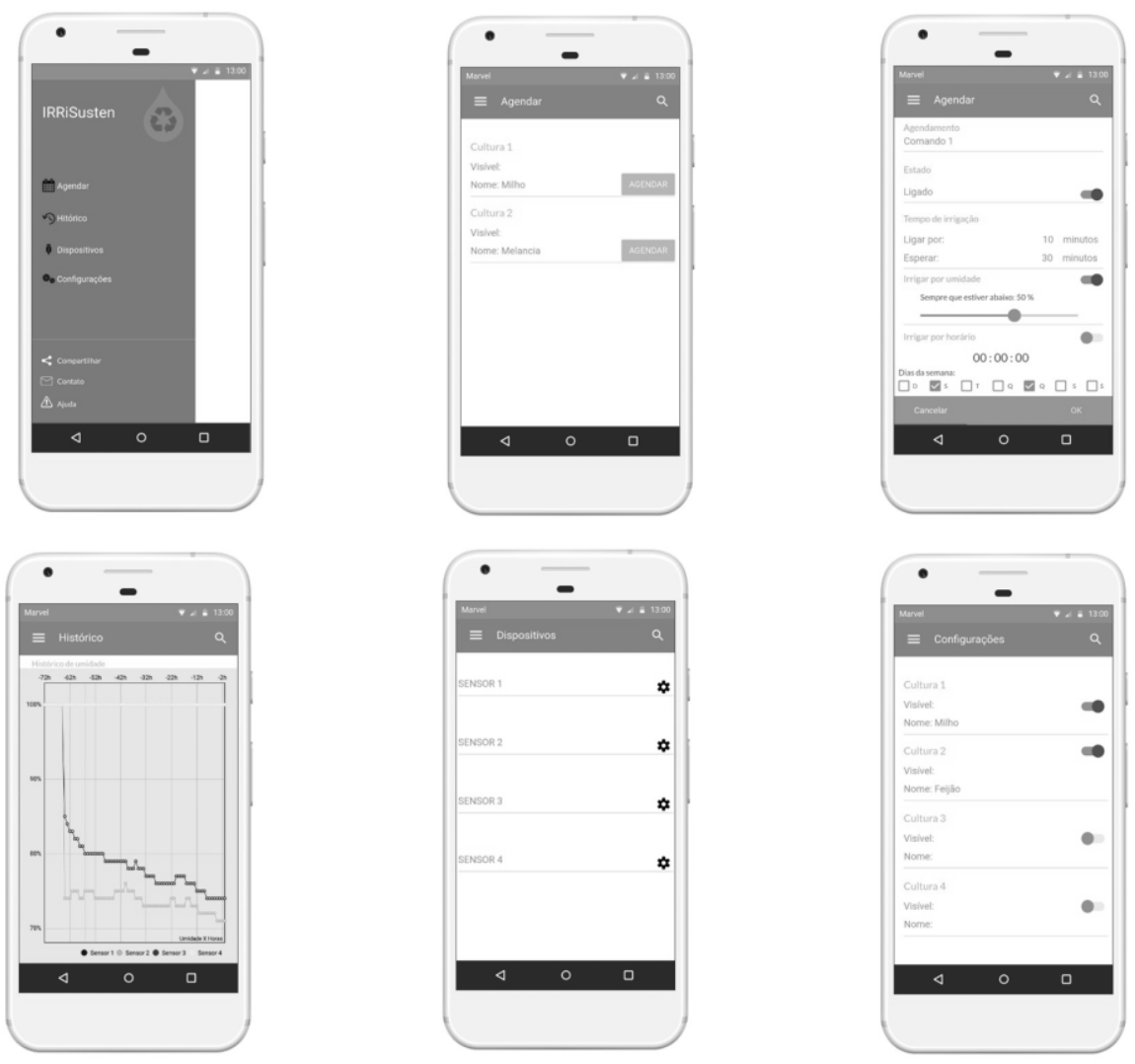

Fonte: Autores

Além do aplicativo o sistema terá a parte física composta dos seguintes componentes: Arduino Uno, módulo sensor de solo, módulo relé de $5 \mathrm{v}$, bateria de $12 \mathrm{v}$, 
led, resistores, válvula solenoide, módulo bluetooth HC-05 ou HC-06, protoboard, jumps e cabo USB. O Arduino possuirá o software que irá interagir com o sensor de umidade, com o módulo relé e com o módulo bluetooth. O sensor de umidade fará a verificação do solo, caso o mesmo esteja com déficit hídrico, o módulo relé ativará a válvula solenoide para a entrada de água, fazendo assim a irrigação da área de plantio. Através do módulo bluetooth será feita a interação entre o software do Arduino e o aplicativo, dando a possibilidade para execução de todas as configurações e comandos que o aplicativo disponibiliza. O circuito da Figura 2 foi construído através do software Fritizing, exemplificando o circuito real que será construído.

Figura 2 - Circuito do Arduino.

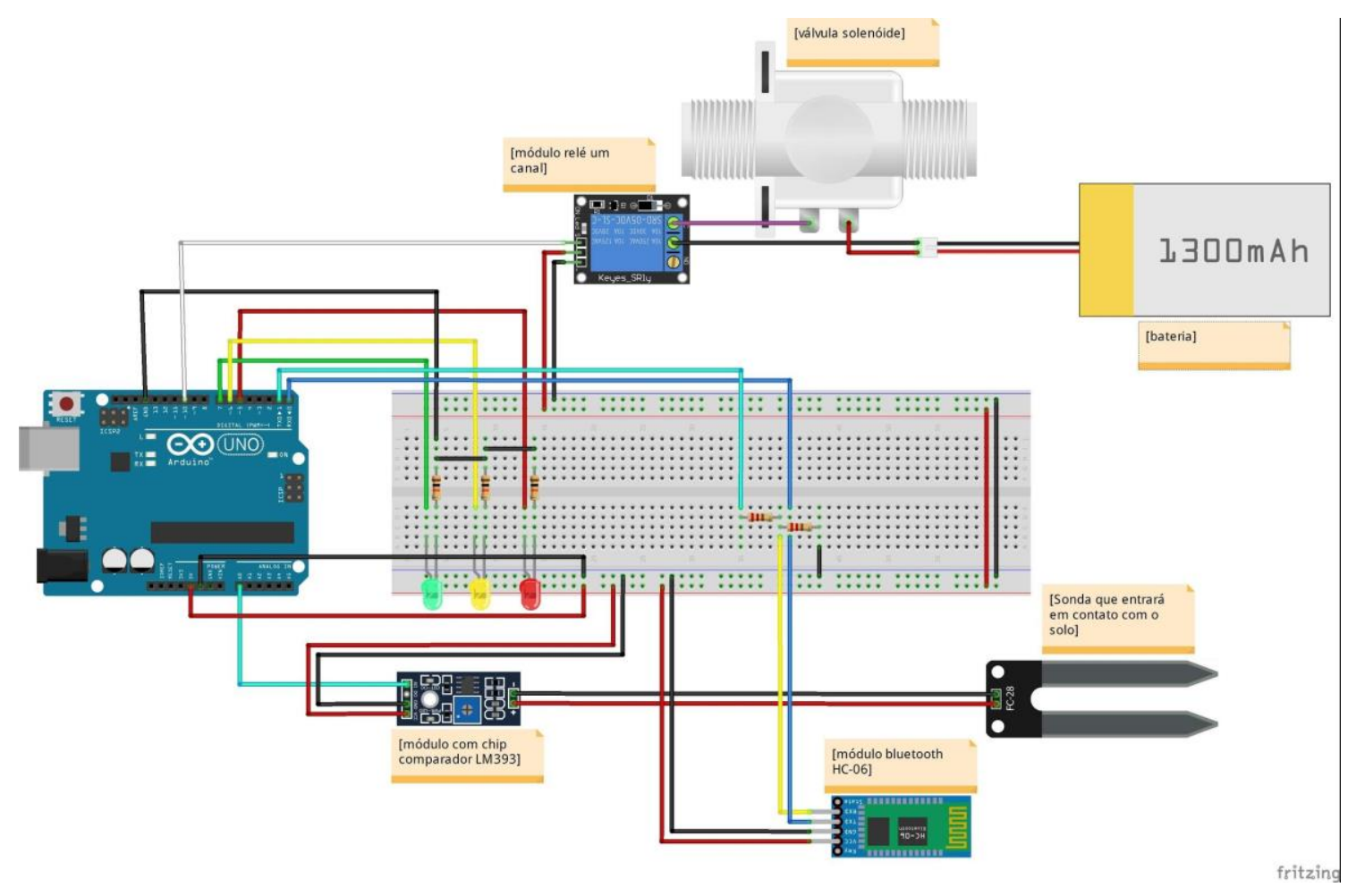

Fonte: Autores

\section{Resultados e Discussão}

Segundo Oliveira (2017), a irrigação se torna flexível, pois a programação pode mudar a qualquer momento devido os sensores servirem para qualquer tipo de cultura e podem ser adaptados a qualquer sistema e programação, independente das regiões. Através da tecnologia de irrigação por sensores de umidade é possível adquirir uma economia de 90\% de aproveitamento de água (CARVALHO; ARAÚJO, 2010). Através desta economia, pode-se verificar que este projeto se torna viável devido também ao custo baixo de implantação. E por fim o jardim, horta, ou outro tipo de cultivo fica melhor cuidado e com uma maior produtividade, pois a falta ou excesso de água no solo pode implicar na ausência de oxigênio da planta, causar doenças, inibir o crescimento, 
entre outros fatores.

\section{Conclusão}

Tais inovações permitem contar com eficiência energética sustentável e melhorar sua performance competitiva, permitem também maior produção, aumento dos lucros e da eficiência econômica. Podendo assim resultar no melhor monitoramento da saúde da plantação e detecção de doenças e contaminações, possibilitando rápida ação dos gestores para a solução do problema.

\section{Referências}

Barbosa, J. W. Sistema de irrigação automatizado utilizando plataforma arduino. Instituto Municipal de Ensino Superior de Assis. 2013.

Carvalho, E. S.; Araujo, L. A. O. Irrigação inteligente. In: Congresso de Iniciação Científica. Instituto Sustentar, 17. 2010, Valinhos - SP. Anuário de Iniciação Científica. Discente. Valinhos- SP: Anhanguera Educacional Ltda., 2010. p. 323 336.

Oliveira, E. E. M. Irrigação automatizada com arduino. 2017. Disponível em: https://www.webartigos.com/artigos/irrigacao-automatizada-com-arduino/150003. Acesso: 05 agost, 2017.

Lucas, P.; Ballay, J.; McManus, M. Trillions: Thriving in the Emerging Information Ecology. Hoboken: Wiley, 2012.

Santaella, L.; Gala, A.; Policarpo, C.; Gazoni, R. Desvelando a Internet das Coisas. Revista Geminis, Ano 4, N. 2, V. 1, p. 19-32, 2013.

Fritizing. Version 0.9.3b. [S.1.]: Friends-of-Fritzing, 2016. Disponível em: <http://fritzing.org/home/>. Acesso em: 06 maio 2018. 